\title{
Measurement of diastolic left ventricular function with ultra-fast phase contrast MRI
}

\author{
Neil Chatterjee ${ }^{1}$, Peter J Weale ${ }^{2}$, Marie Wasielewski ${ }^{3}$, Timothy J Carroll ${ }^{3}$, James Carr ${ }^{3}$, Jeremy Collins ${ }^{3 *}$ \\ From 2011 SCMR/Euro CMR Joint Scientific Sessions \\ Nice, France. 3-6 February 2011
}

\section{Introduction}

MRI is the accepted gold standard for assessment of left ventricular systolic function; however, no standards are available to assess diastolic function at MRI. E/A and E/ e' ratios are currently used in echocardiography to evaluate left ventricular diastolic function. Measuring these ratios with phase contrast MRI may provide a complementary approach to assessing left ventricular function.

\section{Purpose}

To validate E/A and E/e' ratios acquired with phase contrast MRI relative to established values using echocardiography.

\section{Methods}

17 self-reported healthy volunteers were recruited under an IRB approved protocol. Ultra fast phase contrast data was acquired on a $1.5 \mathrm{~T}$ Siemens Aera using both breath-hold (30 frames per cardiac cycle) and free breathing (50 frames per cardiac cycle) paradigms. To measure e' velocities, phase contrast data (Venc $25 \mathrm{~cm} / \mathrm{s}$ ) was acquired in the short axis orientation at a slice position where the myocardium on the apical side of the valve ring was within the slice throughout the cardiac cycle. To measure E and A velocities, phase contrast data (Venc $80 \mathrm{~cm} / \mathrm{s}$ ) was acquired in a single slice parallel to the mitral valve annulus, positioned such that the slice stayed below the valve throughout the entire cardiac cycle. E and A velocities as well as septal and lateral e' velocities were calculated using standard flow postprocessing. 2 subjects were excluded from both analyses due to improper gating, and 4 additional subjects were excluded from the breath hold analysis because there was too much noise to identify e' velocities.

\section{Results}

With free breathing, E/A was measured at $1.7 \pm 0.5$ (range 0.8-2.6), septum E/e' was measured at $5.4 \pm 1.5$ (range 2.5-7.4), and lateral E/e' ratio was measured at $5.1 \pm 1.7$ (range 2.6-8.4). With the breath hold, E/A was measured at $1.5 \pm 0.6$ (range 0.7-2.7), septum E/e' was measured at $6.1 \pm 2.2$ (range 3.6-10.2), and lateral E/e' was measured at $5.4 \pm 2.1$ (range 3.5-10.9). Subjects with an E/e' ratio above 8.0 had normal left atrial size. Figure 1.

\section{Conclusions}

The measured E/A and E/e' values are within normal limits using cutoff values that have been published with echocardiography [1], suggesting that phase contrast MRI may provide a complementary approach to assessing left ventricular diastolic function.

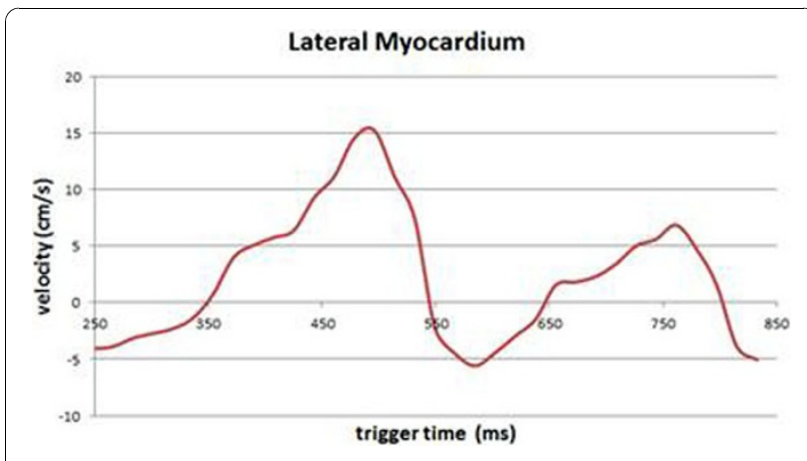

Figure 1 Time/velocity curve showing $e^{\prime}$ and $a^{\prime}$ in lateral myocardium.

${ }^{3}$ Northwestern University, Department of Radiology, Chicago, IL, USA

Full list of author information is available at the end of the article

(c) 2011 Collins et al; licensee BioMed Central Ltd. This is an open access article distributed under the terms of the Creative Commons Attribution License (http://creativecommons.org/licenses/by/2.0), which permits unrestricted use, distribution, and reproduction in any medium, provided the original work is properly cited. 


\section{Author details}

${ }^{1}$ Northwestern University, Feinberg School of Medicine, Chicago, IL, USA.

${ }^{2}$ Siemens Healtcare USA, Chicago, IL, USA. ${ }^{3}$ Northwestern University,

Department of Radiology, Chicago, IL, USA.

Published: 2 February 2011

\section{Reference}

1. Nagueh SF, et al: Recommendations for the evaluation of left ventricular diastolic function by echocardiography. J Am Soc Echocardiogr 2009, 22:107.

doi:10.1186/1532-429X-13-S1-P231

Cite this article as: Chatterjee et al: Measurement of diastolic left ventricular function with ultra-fast phase contrast MRI. Journal of Cardiovascular Magnetic Resonance 2011 13(Suppl 1):P231.

Submit your next manuscript to BioMed Central and take full advantage of:

- Convenient online submission

- Thorough peer review

- No space constraints or color figure charges

- Immediate publication on acceptance

- Inclusion in PubMed, CAS, Scopus and Google Scholar

- Research which is freely available for redistribution

Submit your manuscript at www.biomedcentral.com/submit
() Biomed Central 